\title{
ESTIMASI MODEL REGRESI SEMIPARAMETRIK SPLINE TRUNCATED MENGGUNAKAN METODE MAXIMUM LIKELIHOOD ESTIMATION (MLE)
}

\author{
Narita Yuri Adrianingsih ${ }^{1}$, Andrea Tri Rian Dani ${ }^{2}$ \\ ${ }^{1,2}$ Departemen Statistika, Fakultas Sains dan Analitika Data, Institut Teknologi Sepuluh Nopember \\ e-mail: naritayuria98@gmail.com
}

\begin{abstract}
Abstrak
Pemodelan regresi dengan pendekatan semiparametrik merupakan perpaduan antara dua pendekatan, yaitu pendekatan regresi parametrik dan regresi nonparametrik. Model regresi semiparametrik dapat digunakan jika variabel respon memiliki pola hubungan yang diketahui dengan salah satu atau beberapa variabel prediktor yang digunakan, akan tetapi dengan variabel prediktor yang lainnya tidak dapat diketahui dengan pasti pola hubungannya. Tujuan dari penelitian ini adalah mengkaji bentuk estimasi model regresi semiparametrik spline truncated. Misalkan error random diasumsikan independen, identik, dan berdistribusi normal dengan mean nol dan varians $\sigma^{2}$, maka dengan menggunakan asumsi ini, dapat dilakukan estimasi model regresi semiparametrik spline truncated dengan menggunakan metode Maximum Likelihood Estimation (MLE). Berdasarkan hasil kajian, diperoleh hasil estimasi model regresi semiparametrik spline truncated yaitu $\hat{\boldsymbol{\rho}}=\left(\mathbf{M}^{T} \mathbf{M}\right)^{-1} \mathbf{M}^{T} \mathbf{y}$
\end{abstract}

Kata Kunci: Maximum Likelihood Estimation, Regresi Semiparametrik, Spline Truncated

\begin{abstract}
Regression modeling with a semiparametric approach is a combination of two approaches, namely the parametric regression approach and the nonparametric regression approach. The semiparametric regression model can be used if the response variable has a known relationship pattern with one or more of the predictor variables used, but with the other predictor variables the relationship pattern cannot be known with certainty. The purpose of this research is to examine the estimation form of the semiparametric spline truncated regression model. Suppose that random error is assumed to be independent, identical, and normally distributed with zero mean and variance $\sigma^{2}$, then using this assumption, we can estimate the semiparametric spline truncated regression model using the Maximum Likelihood Estimation (MLE) method. Based on the results, the estimation results of the semiparametric spline truncated regression model were obtained $\hat{\boldsymbol{\rho}}=\left(\mathbf{M}^{T} \mathbf{M}\right)^{-1} \mathbf{M}^{T} \mathbf{y}$
\end{abstract}

Keywords: Maximum Likelihood Estimation, Semiparametric Regression, Spline Truncated

\section{PENDAHULUAN}

Salah satu metode dalam ilmu statistika yang dapat digunakan untuk mendeteksi pola hubungan antara satu atau lebih variabel adalah analisis regresi (Budiantara, 2019). Variabel yang digunakan pada analisis regresi adalah variabel respon dan variabel prediktor. Terdapat beberapa pendekatan dalam pemodelan menggunakan analisis regresi, yaitu regresi parametrik, regresi semiparametrik dan regresi nonparametrik (Dani \& Adrianingsih, 2021).

Pendekatan menggunakan regresi semiparametrik merupakan kombinasi antara pendekatan regresi parametrik dan regresi nonparametrik. Regresi parametrik yaitu bentuk regresi yang di mana bentuk pola hubungan antara variabel respon dan prediktor diketahui, 
sebagai contoh regresi linear, kuadratik, kubik, dan atau lainnya. Sedangkan regresi nonparametrik adalah bentuk regresi yang di mana pola hubungan antar variabel respon dan prediktor tidak diketahui (Eubank, 1999); (Budiantara, 2019) dan (Dani, dkk., 2021). Model regresi semiparametrik digunakan apabila variabel respon memiliki pola hubungan yang diketahui dengan salah satu atau beberapa variabel prediktor, akan tetapi dengan variabel prediktor yang lain tidak diketahui dengan pasti pola hubungannya. Pada kasus riil, seringkali dijumpai fenomena seperti ini, di mana masing-masing variabel prediktor memiliki pola hubungan yang berbeda-beda. Sebagai contoh, adanya kasus-kasus pemodelan yang di mana hubungan antara variabel respon dan prediktor ada yang berbentuk linear (pendekatan parametrik), dan juga ada yang tidak diketahui polanya (pendekatan nonparametrik). Pada bahasan ini, model regresi semiparametrik yang akan dibahas adalah kombinasi komponen parametrik (regresi linear) dan komponen nonparametrik (regresi spline truncated). Nam saya

Regresi linear merupakan salah satu metode regresi yang sangat familiar dan sangat sering kita jumpai dalam prakteknya. Regresi linear digunakan untuk menggambarkan hubungan linear antara variabel prediktor dengan variabel respon (Draper \& Smith, 1992). Spline truncated pertama kali diperkenalkan oleh Whitaker pada Tahun 1923 sebagai pendekatan pola data. Spline truncated merupakan potongan-potongan polinomial yang memiliki sifat tersegmen dan kontinu (Budiantara, 2011). Kelebihan dari spline truncated adalah mampu mengatasi permasalahan pola data yang menunjukkan naik turunnya perubahan pola data yang tajam sehingga dapat menghasilkan kurva yang cenderung mulus (Montoya, dkk., 2014). Adapun Beberapa penelitian sebelumnya yang mengembangkan model regresi nonparametrik spline truncated diantaranya (Wahba, 1990); (Eubank, 1999); (Budiantara, dkk., 2015); (Saputro, dkk., 2018); (Budiantara, 2019) dan (Dani, dkk., 2020).

Pada umumnya, metode estimasi yang sering digunakan adalah Ordinary Least Squares (OLS). Mengingat ada beberapa kelemahan dari metode OLS, maka peneliti tertarik untuk mengkaji bagaimana bentuk estimasi model regresi semiparametrik spline truncated menggunakan metode Maximum Likelihood Estimation (MLE). Metode MLE adalah metode estimasi parameter yang dapat digunakan ketika diketahui distribusi dari error-nya diketahui (Arisandi \& Purhadi, 2014). Pada penelitian ini, distribusi dari error diasumsikan mengikuti distribusi normal. Adapun kelebihan dari metode MLE adalah secara konsep pengerjaan mudah untuk dipahami, dan apabila diperoleh hasil estimasi yang eksplisit, maka dapat dilanjutkan dengan pendekatan numerik untuk memperoleh estimasi dari parameternya.

\section{METODE PENELITIAN}

Pada bagian ini akan dijelaskan tahapan-tahapan estimasi model regresi semiparametrik spline truncated menggunakan metode Maximum Likelihood Estimation (MLE):

1) Diberikan data berpasangan $\left(x_{1 i}, x_{2 i}, \ldots, x_{q i}, z_{1 i}, z_{2 i}, \ldots, z_{p i}, y_{i}\right)$, selanjutnya di asumsikan hubungan antara variabel respon dan prediktor yang mengikuti model regresi semiparametrik multivariabel seperti pada Persamaan (1).

$$
y_{i}=\mu\left(x_{1 i}, x_{2 i}, \ldots, x_{q i}, z_{1 i}, z_{2 i}, \ldots, z_{p i}\right)+\varepsilon_{i}, i=1,2, \ldots, n
$$

di mana ,

$$
\mu\left(x_{1 i}, x_{2 i}, \ldots, x_{q i}, z_{1 i}, z_{2 i}, \ldots, z_{p i}\right)=f\left(x_{1 i}, x_{2 i}, \ldots, x_{q i}\right)+h\left(z_{1 i}, z_{2 i}, \ldots, z_{p i}\right)
$$


2) Menghampiri kurva regresi komponen parametrik dengan bentuk regresi linear.

$$
f\left(x_{1 i}, x_{2 i}, \ldots, x_{q i}\right)=\beta_{0}+\beta_{1} x_{1 i}+\beta_{2} x_{2 i}+\ldots+\beta_{q} x_{q i}
$$

3) Menghampiri kurva regresi komponen nonparametrik menggunakan spline truncated dengan knot sebanyak $r$.

$$
h\left(z_{1 i}, z_{2 i}, \ldots, z_{p i}\right)=\sum_{j=1}^{p} \delta_{j} z_{j i}+\sum_{j=1}^{p} \sum_{k=1}^{r} \delta_{j(k+1)}\left(z_{j i}-K_{j k}\right)_{+}
$$

4) Menuliskan model umum regresi semiparametrik spline truncated

$$
\begin{aligned}
y_{i} & =f\left(x_{1 i}, x_{2 i}, \ldots, x_{q i}\right)+h\left(z_{1 i}, z_{2 i}, \ldots, z_{p i}\right)+\varepsilon_{i} \\
& =\left[\beta_{0}+\beta_{1} x_{1 i}+\ldots+\beta_{q} x_{q i}\right]+\left[\sum_{j=1}^{p} \delta_{j} z_{j i}+\sum_{j=1}^{p} \sum_{k=1}^{r} \delta_{j(k+1)}\left(z_{j i}-K_{j k}\right)_{+}\right]+\varepsilon_{i}
\end{aligned}
$$

Maka berdasarkan Persamaan (2), dapat ditulis dalam bentuk notasi matriks.

$$
\mathbf{y}=\mathbf{X} \boldsymbol{\beta}+\mathbf{Z} \boldsymbol{\delta}+\boldsymbol{\varepsilon}
$$

5) Menuliskan error dari model regresi semiparametrik spline truncated.

$$
\boldsymbol{\varepsilon}=\mathbf{y}-(\mathbf{X} \boldsymbol{\beta}+\mathbf{Z} \boldsymbol{\delta})
$$

6) Menuliskan jumlah kuadrat error ke dalam bentuk norm kuadrat vektor $\boldsymbol{\varepsilon}$.

$$
\begin{aligned}
\|\boldsymbol{\varepsilon}\|^{2} & =\|\mathbf{y}-(\mathbf{X} \boldsymbol{\beta}+\mathbf{Z} \boldsymbol{\delta})\|^{2} \\
& =\|\mathbf{y}-\mathbf{M} \boldsymbol{\rho}\|^{2}
\end{aligned}
$$

Dengan,

$$
\mathbf{M}=[\mathbf{X} \quad \vdots \mathbf{Z}]
$$

Dapat dijabarkan $\mathbf{X}=\left[\begin{array}{cccc}1 & x_{11} & \cdots & x_{q 1} \\ 1 & x_{12} & \cdots & x_{q 2} \\ \vdots & \vdots & \ddots & \vdots \\ 1 & x_{1 n} & \cdots & x_{q n}\end{array}\right]$

dan

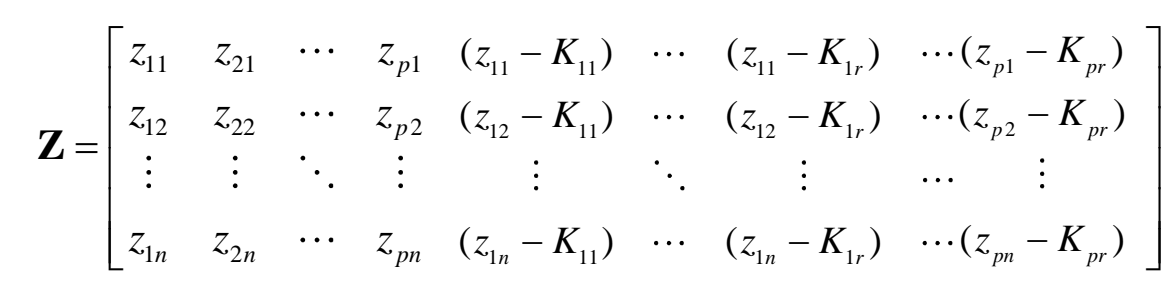

Sehingga, 


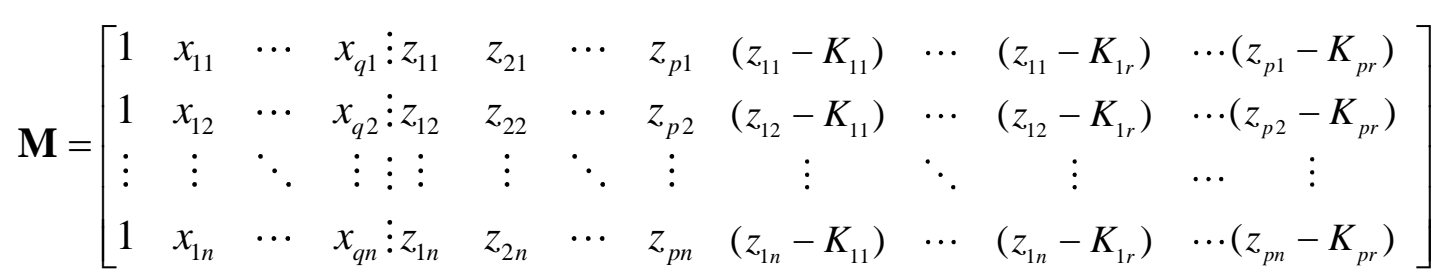

Kemudian $\boldsymbol{\rho}=\left[\begin{array}{l}\boldsymbol{\beta} \\ \boldsymbol{\delta}\end{array}\right]$.

7) Menyajikan bentuk optimasi untuk mendapatkan estimator $\boldsymbol{\rho}$ dengan menggunakan metode Maximum Likelihood Estimation (MLE).

$$
\underset{\rho \in R}{\operatorname{Max}} l(\boldsymbol{\rho})
$$

8) Menyelesaikan optimasi pada langkah (8) dengan melakukan derivatif parsial.

$$
\frac{\partial l(\boldsymbol{\rho})}{\partial \boldsymbol{\rho}}=0
$$

9) Mendapatkan estimator dari $\hat{\boldsymbol{\rho}}$.

\section{HASIL DAN PEMBAHASAN}

Diberikan data berpasangan $\left(x_{1 i}, x_{2 i}, \ldots, x_{q i}, z_{1 i}, z_{2 i}, \ldots, z_{p i}, y_{i}\right)$ yang memiliki hubungan, selanjutnya diasumsikan pola hubungannya mengikuti model regresi semiparametrik. Komponen $\left(x_{1 i}, x_{2 i}, \ldots, x_{q i}, z_{1 i}, z_{2 i}, \ldots, z_{p i}\right)$ merupakan variabel prediktor dan $\left(y_{i}\right)$ adalah variabel respon. Model regresi semiparametrik spline truncated dituliskan sebagai berikut:

$$
\begin{aligned}
& y_{i}=\mu\left(x_{1 i}, x_{2 i}, \ldots, x_{q i}, z_{1 i}, z_{2 i}, \ldots, z_{p i}\right)+\varepsilon_{i}, i=1,2, \ldots, n \\
& y_{i}=\mu\left(x_{i}, z_{i}\right)+\varepsilon_{i}
\end{aligned}
$$

di mana: $\mu\left(x_{1 i}, x_{2 i}, \ldots, x_{q i}, z_{1 i}, z_{2 i}, \ldots, z_{p i}\right)=f\left(x_{1 i}, x_{2 i}, \ldots, x_{q i}\right)+h\left(z_{1 i}, z_{2 i}, \ldots, z_{p i}\right)$.

Selanjutnya $\quad \varepsilon_{i}$ diasumsikan $\operatorname{IIDN}\left(0, \sigma^{2}\right)$ sehingga $\varepsilon_{i} \sim \operatorname{IIDN}\left(0, \sigma^{2}\right)$. Kurva regresi semiparametrik $\mu\left(x_{i}, z_{i}\right)$ diasumsikan bersifat aditif sedemikian sehingga dapat dituliskan:

$$
\mu\left(x_{i}, z_{i}\right)=f\left(x_{1 i}\right)+f\left(x_{2 i}\right)+\ldots+f\left(x_{q i}\right)+h\left(z_{1 i}\right)+h\left(z_{2 i}\right)+\ldots+h\left(z_{p i}\right)
$$

Kurva regresi pada Persamaan (3) yaitu $\mu\left(x_{i}, z_{i}\right)$ disebut dengan kurva regresi semiparametrik spline truncated, di mana dapat ditulis menjadi:

$$
\mu\left(x_{i}, z_{i}\right)=\sum_{l=1}^{q} f\left(x_{q i}\right)+\sum_{j=1}^{p} h\left(z_{p i}\right)
$$


Komponen kurva regresi $\sum_{l=1}^{q} f\left(x_{q i}\right)$ merupakan komponen kurva regresi linier dan $\sum_{j=1}^{p} h\left(z_{p i}\right)$ merupakan komponen kurva regresi spline truncated.

Komponen kurva regresi linier yaitu $\sum_{l=1}^{q} f\left(x_{q i}\right)$ pada Persamaan (4) dapat dijabarkan dalam bentuk matriks menjadi:

$$
\left[\begin{array}{c}
y_{1} \\
y_{2} \\
\vdots \\
y_{n}
\end{array}\right]=\left[\begin{array}{cccc}
1 & x_{11} & \cdots & x_{q 1} \\
1 & x_{12} & \cdots & x_{q 2} \\
\vdots & \vdots & \ddots & \vdots \\
1 & x_{1 n} & \cdots & x_{q n}
\end{array}\right]\left[\begin{array}{c}
\beta_{0} \\
\beta_{1} \\
\vdots \\
\beta_{q}
\end{array}\right]
$$

Selanjutnya matriks diatas dapat diringkas menjadi $\mathbf{y}=\mathbf{X} \boldsymbol{\beta}$, di mana $\mathbf{y}$ merupakan vektor variabel respon berukuran $(n \times 1), \mathbf{X}$ merupakan matriks berukuran $n \times(q+1), \quad \boldsymbol{\beta}$ merupakan vektor parameter koefisien regresi linier yang akan diestimasi dan berukuran $(q+1) \times 1$.

Komponen kurva regresi spline truncated $\sum_{j=1}^{p} h\left(z_{p i}\right)$ pada Persamaan (4) dapat dijabarkan dalam bentuk matriks menjadi:

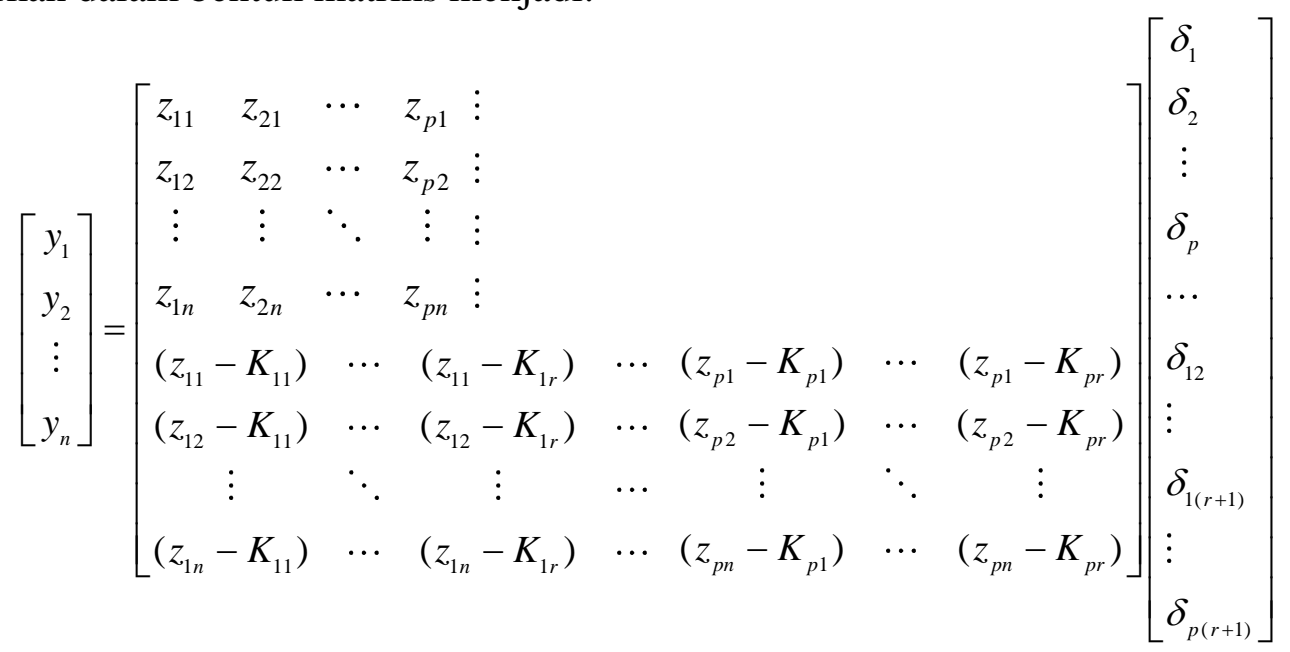

Selanjutnya matriks diatas dapat diringkas menjadi $\mathbf{y}=\mathbf{Z} \boldsymbol{\delta}$. Berdasarkan Persamaan (4) dan bentuk penjabarannya, maka dapat dituliskan model regresi semiparametrik spline truncated seperti pada Persamaan (7).

$$
\mathbf{y}=\mathbf{X} \boldsymbol{\beta}+\mathbf{Z} \boldsymbol{\delta}+\boldsymbol{\varepsilon}
$$

Komponen $\mathbf{X} \boldsymbol{\beta}$ merupakan komponen parametrik, sedangkan komponen $\mathbf{Z} \boldsymbol{\delta}$ merupakan komponen nonparametrik. Berdasarkan Persamaan (5), maka dapat disajikan bentuk errornya sebagai berikut:

$$
\boldsymbol{\varepsilon}=\mathbf{y}-(\mathbf{X} \boldsymbol{\beta}+\mathbf{Z} \boldsymbol{\delta})
$$

Jumlah kuadrat error dalam bentuk norm kuadrat vektor $\boldsymbol{\varepsilon}$ dituliskan pada Persamaan (6). 


$$
\begin{aligned}
\|\boldsymbol{\varepsilon}\|^{2} & =\|\mathbf{y}-(\mathbf{X} \boldsymbol{\beta}+\mathbf{Z} \boldsymbol{\delta})\|^{2} \\
& =\|\mathbf{y}-\mathbf{M} \boldsymbol{\rho}\|^{2}
\end{aligned}
$$

di mana ,

$$
\mathbf{M}=\left[\begin{array}{lll}
\mathbf{X} & \vdots & \mathbf{Z}
\end{array}\right] \text { dan } \boldsymbol{\rho}=\left[\begin{array}{l}
\boldsymbol{\beta} \\
\boldsymbol{\delta}
\end{array}\right]
$$

Metode estimasi yang akan digunakan adalah Maximum Likelihood Estimation (MLE) dengan error-nya diasumsikan $\varepsilon_{i} \sim \operatorname{IIDN}\left(0, \sigma^{2}\right)$, maka dapat kita tuliskan fungsi distribusi probabilitas dari $\varepsilon_{i}$, di mana $i=1,2, \ldots, n$ diberikan sebagai berikut:

$$
f\left(\varepsilon_{i}\right)=\frac{1}{\sqrt{2 \pi \sigma^{2}}} e^{-\frac{\varepsilon_{i}^{2}}{2 \sigma^{2}}} I_{(-\infty, \infty)}\left(\varepsilon_{i}\right)
$$

Berdasarkan Persamaan (7) maka dapat kita tuliskan fungsi likelihood nya:

$$
\begin{aligned}
L(\boldsymbol{\rho}) & =\prod_{i=1}^{n} f\left(\varepsilon_{i}\right) \\
& =\prod_{i=1}^{n}\left(\frac{1}{\sqrt{2 \pi \sigma^{2}}} e^{-\frac{\varepsilon_{i}^{2}}{2 \sigma^{2}}}\right) \\
& =\left(2 \pi \sigma^{2}\right)^{-\frac{n}{2}} e^{-\frac{1}{2 \sigma^{2}} \sum_{i=1}^{n} \varepsilon_{i}^{2}} \\
& =\left(2 \pi \sigma^{2}\right)^{-\frac{n}{2}} e^{-\frac{1}{2 \sigma^{2}}\|\|^{2}}
\end{aligned}
$$

Dengan $\|\boldsymbol{\varepsilon}\|^{2}=\boldsymbol{\varepsilon}^{T} \boldsymbol{\varepsilon}=[\mathbf{y}-(\mathbf{X} \boldsymbol{\beta}+\mathbf{Z} \boldsymbol{\delta})]^{T}[\mathbf{y}-(\mathbf{X} \boldsymbol{\beta}+\mathbf{Z} \boldsymbol{\delta})]$ atau dapat kita ringkas dan tuliskan $\|\boldsymbol{\varepsilon}\|^{2}=\|\mathbf{y}-\mathbf{M} \boldsymbol{\rho}\|^{2}$. Selanjutnya berdasarkan Persamaan (8), maka dapat diperoleh fungsi log Likelihood nya:

$$
\begin{aligned}
l(\boldsymbol{\rho}) & =\log L(\boldsymbol{\rho}) \\
& =-\frac{n}{2} \log 2 \pi \sigma^{2}-\frac{1}{2 \sigma^{2}}\|\mathbf{y}-\mathbf{M} \boldsymbol{\rho}\|^{2} \\
& =-\frac{n}{2} \log 2 \pi \sigma^{2}-\frac{1}{2 \sigma^{2}}(\mathbf{y}-\mathbf{M} \boldsymbol{\rho})^{T}(\mathbf{y}-\mathbf{M} \boldsymbol{\rho})
\end{aligned}
$$

Fungsi $l(\boldsymbol{\rho})$ selanjutnya diderivatifkan secara parsial terhadap parameternya yaitu $\boldsymbol{\rho}$, kemudian disamadengankan nol, sehingga diperoleh:

$$
\begin{aligned}
\frac{\partial l(\boldsymbol{\rho})}{\partial \boldsymbol{\rho}} & =\frac{\partial}{\partial \boldsymbol{\rho}}\left(-\frac{n}{2} \log 2 \pi \sigma^{2}-\frac{1}{2 \sigma^{2}}(\mathbf{y}-\mathbf{M} \boldsymbol{\rho})^{T}(\mathbf{y}-\mathbf{M} \boldsymbol{\rho})\right) \\
& =\frac{\partial}{\partial \boldsymbol{\rho}}\left(-\frac{1}{2 \sigma^{2}}(\mathbf{y}-\mathbf{M} \hat{\boldsymbol{\rho}})^{T}(\mathbf{y}-\mathbf{M} \hat{\boldsymbol{\rho}})\right)=0
\end{aligned}
$$

Selanjutnya untuk mendapatkan estimasi untuk $\boldsymbol{\rho}$, dapat diselesaikan dengan: 


$$
\frac{\partial}{\partial \boldsymbol{\rho}}\left(\mathbf{y}^{T} \mathbf{y}-2 \hat{\boldsymbol{\rho}}^{T} \mathbf{M}^{T} \mathbf{y}+\hat{\boldsymbol{\rho}}^{T} \mathbf{M}^{T} \mathbf{M} \hat{\boldsymbol{\rho}}\right)=0 \rightarrow-2 \mathbf{M}^{T} \mathbf{y}+2\left(\mathbf{M}^{T} \mathbf{M}\right) \hat{\boldsymbol{\rho}}=0
$$

Dengan menyelesaikan Persamaan (9), maka akan didapatkan estimasi untuk $\hat{\boldsymbol{\rho}}$ sebagai berikut:

Dengan $\hat{\boldsymbol{\rho}}=\left[\begin{array}{c}\hat{\boldsymbol{\beta}} \\ \cdots \\ \hat{\boldsymbol{\delta}}\end{array}\right]$

$$
\hat{\boldsymbol{\rho}}=\left(\mathbf{M}^{T} \mathbf{M}\right)^{-1} \mathbf{M}^{T} \mathbf{y}
$$

\section{KESIMPULAN}

Berdasarkan hasil kajian yang dilakukan, diperoleh hasil estimasi parameter model regresi semiparametrik spline truncated dengan menggunakan metode Maximum Likelihood Estimation (MLE) dengan diasumsikan distribusi dari error mengikuti distribusi Normal sebagai berikut:

$$
\hat{\boldsymbol{\rho}}=\left(\mathbf{M}^{T} \mathbf{M}\right)^{-1} \mathbf{M}^{T} \mathbf{y}
$$

di mana,

$$
\hat{\boldsymbol{\rho}}=\left[\begin{array}{l}
\hat{\boldsymbol{\beta}} \\
\cdots \\
\hat{\boldsymbol{\delta}}
\end{array}\right]
$$

\section{DAFTAR PUSTAKA}

Arisandi, R. dan Purhadi., (2014), "Estimasi Parameter dan Pengujian Hipotesis Model Regresi Burr Tiga Parameter Tipe XII", Prosiding Seminar Nasional Matematika, Universitas Jember, hal: 145-166.

Budiantara, I. N., (2011), Penelitian Bidang Regresi Spline Menuju Terwujudnya Penelitian Statistika yang Mandiri dan Berkarakter, Prosiding Seminar Nasional FMIPA Undiksha, hal: 09-28.

Budiantara, I. N., Ratnasari, V., Madu, R., dan Zain, I., (2015), "The Combination of Spline and Kernel Estimator for Nonparametric Regression and Its Properties," Applied Mathematical Sciences, Vol. 09, No. 22, hal: 6083-6094.

Budiantara, I. N., (2019), Regresi Nonparametrik Spline Truncated, Surabaya: ITS Press.

Dani, A. T. R., Adrianingsih, N. Y., \& Ainurrochmah, A., (2020), "Pengujian Hipotesis Simultan Model Regresi Nonparametrik Spline Truncated dalam Pemodelan Kasus Ekonomi," Jambura Journal of Probability and Statistics, Vol. 01, No. 02, hal:98106

Dani, A. T. R. dan Adrianingsih, N. Y., (2021), "Pemodelan Regresi Nonparametrik dengan Estimator Spline Truncated dan Deret Fourier," Jambura Journal of Mathematics, Vol. 03, No. 01, hal. 26-36.

Dani, A. T. R., Ratnasari, V., dan Budiantara, I. N., (2021), "Optimal Knots Point and Bandwidth Selection in Modeling Mixed Estimator Nonparametric Regression," IOP Conf. Ser. Mater. Sci. Eng., vol. 1115.

Draper, N. R. dan Smith, H., (1992), Applied Regression Analysis: Third Edition, USA: John Wiley \& Sons, Inc. 
Eubank, R. L., (1999), Nonparametric Regression and Spline Smoothing, New York: Marcel Dekker.

Montoya, E. L., Ulloa, N., dan Miler, V., (2014), "A Simulation Study Comparing Knot Selection Methods with Equality Spaced Knots in a Penalized Regression Spline," International Journal of Statistics and Probability, Vol. 03, No. 03, hal: 96-110.

Saputro, D. R. S., Demu, K. R., dan Widyaningsih, P., (2018), "Nonparametric Truncated Spline Regression Model on the Data of Human Development Index (HDI) in Indonesia," $2^{\text {nd }}$ International Conference on Statistics, Mathematics, Teaching and Research, IOP Conf. Series: Journal of Physics, hal: 01-04.

Wahba, G., (1990), Spline Models for Observational Data, Pennsylvania: SIAM. 